\title{
Control strategies for active power filters
}

\author{
F. Barrero ${ }^{1}$, E. Romero ${ }^{1}$ and M. I. Milanés ${ }^{1}$ \\ ${ }^{1}$ Department of Electronic and Electromechanical Engineering \\ School of Industrial Engineering \\ University of Extremadura \\ Avda Elvas s/n, 06006 Badajoz (SPAIN) \\ phone:+34 924289600, fax:+34 924289601, \\ e-mail: fbarrero@unex.es, eromero@unex.es, milanes@unex.es
}

\begin{abstract}
In this paper a comparison between strategies for extracting the three-phase reference currents for active power filters is shown. The performance of these strategies will be evaluated under different source and load conditions. The study has been applied to a three-phase four-wire system in order to include imbalance.
\end{abstract}

It will be shown that under balanced and sinusoidal voltages, harmonic cancellation and reactive power compensation can be achieved by all the methods. However, when the voltages are distorted and/or unbalanced, the compensation capabilities are not equivalent.

It will be proved that some strategies do not offer an adequate solution when the mains are not ideal, including harmonics or imbalance.

\section{Keywords}

Active filtering, reference current extraction, $\mathrm{p}-\mathrm{q}$ theory, $i_{d}-i_{q}$ method, unity power factor method, perfect harmonic cancellation method.

\section{Introduction}

Power electronics converters, more and more widely used in industrial, commercial as well as domestic applications, suffer from the problem of drawing non sinusoidal current and reactive power from the source. This behavior causes voltage distortion that affects to another loads connected at the same point of common coupling (PCC). Active power filters are researched and developed as a viable alternative over the conventional methods to solve this problem. Of course, the size and cost of active power filters depends on harmonics and reactive power to be compensated.

The control strategy for a shunt active power filter (Figure 1) generates the reference current that must be provided by the power filter to compensate reactive power and harmonics currents demanded by the load.

This implies a set of source current in the phase domain, that will be tracked generating the switching signals applied to the electronic converter (heart of the active power filter) by means of the appropriate closed-loop switching control technique, like hysteresis band control.
First, this paper presents a revision of four control strategies for the extraction of the reference currents for an active power filter connected to a three-phase fourwired source that supplies to a nonlinear load (Figure 1). The four strategies that have been compared are:

- Instantaneous active and reactive power (p-q method).

- Instantaneous direct and quadrature current $\left(i_{d}-i_{q}\right.$ method).

- Unity Power Factor (UPF) method.

- Perfect Harmonic Cancellation (PHC) method.

Finally, comparative evaluation is performed by means of simulation study under both ideal and distorted mains voltage conditions and various load conditions.

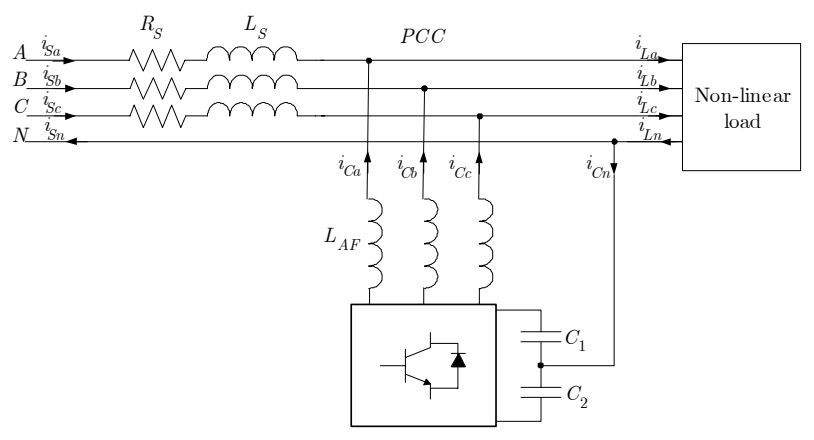

Fig. 1. Three-phase four-wire source with non-linear load and shunt active power filter.

\section{Instantaneous p-q strategy}

Most of the APF's (active power filters) developed are based on the instantaneous reactive power theory (or $\mathrm{p}-\mathrm{q}$ theory) to calculate the desired compensation current. This theory was proposed first by Akagi and his coworkers in 1984 [1]. Since then various interpretations and improvements of this method have been presented [2], [3]. In this method, a set of voltages $\left(u_{a}, u_{b}, u_{c}\right)$ and currents $\left(i_{a}, i_{b}, i_{c}\right)$ from a three-phase four-wire system, are first transformed into three-axis representation $\alpha-\beta-0$, using the following power invariant: 


$$
\begin{gathered}
{\left[\begin{array}{l}
u_{0} \\
u_{\alpha} \\
u_{\beta}
\end{array}\right]=\mathbf{C}\left[\begin{array}{l}
u_{a} \\
u_{b} \\
u_{c}
\end{array}\right] ;\left[\begin{array}{c}
i_{0} \\
i_{\alpha} \\
i_{\beta}
\end{array}\right]=\mathbf{C}\left[\begin{array}{c}
i_{a} \\
i_{b} \\
i_{c}
\end{array}\right]} \\
\mathbf{C}=\sqrt{\frac{2}{3}}\left[\begin{array}{ccc}
\frac{1}{\sqrt{2}} & \frac{1}{\sqrt{2}} & \frac{1}{\sqrt{2}} \\
1 & -\frac{1}{2} & -\frac{1}{2} \\
0 & \frac{\sqrt{3}}{2} & -\frac{\sqrt{3}}{2}
\end{array}\right]
\end{gathered}
$$

where $\mathbf{C}$ is the so called transformation matrix: $\|\mathbf{C}\|=1 ; \mathbf{C}^{-1}=\mathbf{C}^{T}$.

The generalized instantaneous active power, $p$, and instantaneous reactive power, $q$, defined in [2], [3], in terms of the $\alpha-\beta-0$ components, are given by the following expressions:

$$
p=\mathbf{u} \cdot \mathbf{i}=u_{a} i_{a}+u_{b} i_{b}+u_{c} i_{c}=u_{0} i_{0}+u_{\alpha} i_{\alpha}+u_{\beta} i_{\beta}
$$

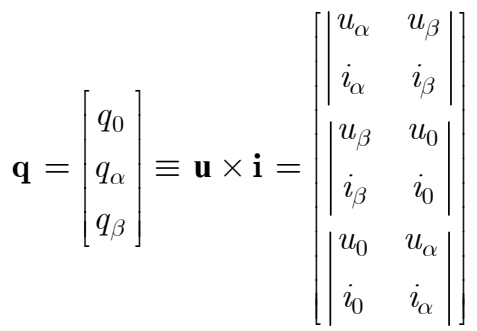

$$
\begin{aligned}
& q=\|\mathbf{q}\|=\sqrt{q_{0}^{2}+q_{\alpha}^{2}+q_{\beta}^{2}}
\end{aligned}
$$

The instantaneous three-phase active power has two components: the instantaneous zero-sequence active power, $p_{0}$, and the instantaneous active power due to positive and negative sequence components, $p_{e}$. According to this:

$$
\begin{aligned}
p & =p_{0}+p_{e} \\
p_{0} & =u_{0} i_{0} \\
p_{e} & =u_{\alpha} i_{\alpha}+u_{\beta} i_{\beta}
\end{aligned}
$$

Moreover, each power component have, in its turn, a mean value or $d c$ component and an oscillating value or $a c$ component. For the system shown in Figure 1, the power components required by the load are:

$$
p_{L}=\bar{p}_{L}+\tilde{p}_{L} \quad \mathbf{q}_{L}=\overline{\mathbf{q}}_{L}+\tilde{\mathbf{q}}_{L}
$$

The objective is to get the source to give only the constant active power demanded by the load, $\bar{p}_{L e}+\bar{p}_{L 0}$. In addition, the source must deliver no zero-sequence active power, $i_{S 0 \text { ref }}=0$. Therefore, the reference source currents in the $\alpha-\beta-0$ frame can be determined by [8]:

$$
\left[\begin{array}{c}
i_{S 0_{\text {ref }}} \\
i_{S \alpha_{\text {ref }}} \\
i_{S \beta_{\text {ref }}}
\end{array}\right]=\frac{\bar{p}_{L}+\bar{p}_{L 0}}{u_{\alpha}^{2}+u_{\beta}^{2}}\left[\begin{array}{c}
0 \\
u_{\alpha} \\
u_{\beta}
\end{array}\right]
$$

\section{3. $i_{d}-i_{q}$ method}

This method is also known as Synchronous Reference Frame (SRF) [6], [7]. Here, the reference frame $d-q(d$ direct axis, $q$ quadrature axis) is determined by the angle $\theta$ with respect to the $\alpha-\beta$ frame used in the $p-q$ theory. The transformation from $\alpha-\beta-0$ frame to $d-q$ frame is given by:

$$
\left[\begin{array}{l}
i_{0} \\
i_{d} \\
i_{q}
\end{array}\right]=\left[\begin{array}{ccc}
1 & 0 & 0 \\
0 & \cos \theta & \operatorname{sen} \theta \\
0 & -\operatorname{sen} \theta & \cos \theta
\end{array}\right]\left[\begin{array}{l}
i_{0} \\
i_{\alpha} \\
i_{\beta}
\end{array}\right]
$$

If $d$ axis is in the direction of the voltage space vector, and taking into account that the zero-sequence component is invariant, the transformation is given by:

$$
\begin{gathered}
{\left[\begin{array}{l}
i_{d} \\
i_{q}
\end{array}\right]=\mathbf{S}\left[\begin{array}{c}
i_{\alpha} \\
i_{\beta}
\end{array}\right]} \\
\mathbf{S}=\frac{1}{\sqrt{u_{\alpha}^{2}+u_{\beta}^{2}}}\left[\begin{array}{cc}
u_{\alpha} & u_{\beta} \\
-u_{\beta} & u_{\alpha}
\end{array}\right]
\end{gathered}
$$

where $\mathbf{S}$, the transformation matrix, has the properties: $\mathbf{S}=1 ; \mathbf{S}^{-1}=\mathbf{S}^{\mathrm{T}}$.

Each one of the current components $\left(i_{d}, i_{q}\right)$ has an average value or $d c$ component and an oscillating value or ac component:

$$
\begin{aligned}
& i_{d}=\overline{i_{d}}+\tilde{i}_{d} \\
& i_{q}=\overline{i_{d}}+\tilde{i}_{q}
\end{aligned}
$$

The compensating strategy (for harmonic reduction and reactive power compensation) implies that the source must only delivers the mean value of the direct-axis component of load current. Therefore, the compensator current will be:

$$
\begin{aligned}
i_{C 0} & =i_{L 0} \\
i_{C d} & =\tilde{i}_{L d} \\
i_{C q} & =\bar{i}_{L q}+\tilde{i}_{L q}
\end{aligned}
$$

From equation (8) the direct-axis component of the load current is:

$i_{L d}=\frac{u_{\alpha} \cdot i_{L \alpha}+u_{\beta} \cdot i_{L \beta}}{\sqrt{u_{\alpha}^{2}+u_{\beta}^{2}}}=\frac{p_{L e}}{\sqrt{u_{\alpha}^{2}+u_{\beta}^{2}}}=\bar{i}_{L d}+\tilde{i}_{L d}$ 
The $d c$ component of the above equation will be:

$$
\bar{i}_{L d}=\frac{\bar{p}_{L e}}{\left(\sqrt{u_{\alpha}^{2}+u_{\beta}^{2}}\right)_{d c}}
$$

where the subscript 'dc' must be understood as the mean value of the expression into brackets.

The reference source current must be in phase with the source voltage and no unbalanced, therefore it will be obtained, in the $\alpha-\beta-0$ frame, multiplying (12) for an unitary vector in the direction of voltage source space vector, excluded the zero-sequence component:

$\mathbf{i}_{S_{\text {ref }}}=\bar{i}_{L d} \frac{1}{\sqrt{u_{\alpha}^{2}+u_{\beta}^{2}}}\left[\begin{array}{c}0 \\ u_{\alpha} \\ u_{\beta}\end{array}\right]=\frac{\bar{p}_{L e}}{\left(\sqrt{u_{\alpha}^{2}+u_{\beta}^{2}}\right)_{d c}} \frac{1}{\sqrt{u_{\alpha}^{2}+u_{\beta}^{2}}}\left[\begin{array}{c}0 \\ u_{\alpha} \\ u_{\beta}\end{array}\right]$

\section{UPF strategy}

The compensation strategy known as the unity power factor (UPF) method has the objective that the load plus the compensator must be viewed by the source as a resistance [8], [9]. This method is also known as the 'voltage synchronization method' because the current source space vector is in phase with the voltage source space vector. The compensator current will be:

$$
\mathbf{i}_{C}=\mathbf{i}_{L}-\mathbf{i}_{S \text { ref }}=\mathbf{i}_{L}-K \cdot \mathbf{u}
$$

where $K$ is a constant which value depends on the source voltage and the load.

The power delivered by the source will be:

$$
p_{S}=\mathbf{u} \cdot \mathbf{i}_{S}=\mathbf{u} \cdot K \cdot \mathbf{u}=K\left(u_{0}^{2}+u_{\alpha}^{2}+u_{\beta}^{2}\right)
$$

The conductance $K$ can be determined with the criterion that the power delivered by the source equals the $\mathrm{dc}$ component of the instantaneous active power of the load, therefore:

$$
K=\frac{\bar{p}_{L e}+\bar{p}_{L 0}}{\left(u_{0}^{2}+u_{\alpha}^{2}+u_{\beta}^{2}\right)_{d c}}
$$

Finally, the reference current source will be given by:

$$
\left[\begin{array}{c}
i_{S 0_{\text {ref }}} \\
i_{S \alpha_{\text {ref }}} \\
i_{S \beta_{\text {ref }}}
\end{array}\right]=K\left[\begin{array}{l}
u_{0} \\
u_{\alpha} \\
u_{\beta}
\end{array}\right]=\frac{\bar{p}_{L e}+\bar{p}_{L 0}}{\left(u_{0}^{2}+u_{\alpha}^{2}+u_{\beta}^{2}\right)_{d c}}\left[\begin{array}{c}
u_{0} \\
u_{\alpha} \\
u_{\beta}
\end{array}\right]
$$

\section{PHC strategy}

This method can be considered as a modification of the previously presented theories and has the objective to compensate all the harmonic currents and reactive power demanded by the load; therefore, the current source will be balanced and will be in phase with the fundamental component of the voltage source, excluded the zerosequence component [8].

The compensator reference current will be given by:

$$
\mathbf{i}_{C}=\mathbf{i}_{L}-\mathbf{i}_{S \text { ref }}=\mathbf{i}_{L}-K \cdot \mathbf{u}_{\alpha \beta 1}
$$

where $\mathbf{u}_{\alpha \beta 1}$ is the voltage source space vector with only fundamental component without zero-sequence component.

The compensator reference current will be given by:

$$
p_{S}=\mathbf{u}_{\alpha \beta 1} \cdot \mathbf{i}_{S}=\mathbf{u}_{\alpha \beta 1} \cdot K \cdot \mathbf{u}_{\alpha \beta 1}=K\left(u_{\alpha 1}^{2}+u_{\beta 1}^{2}\right)
$$

The constant $K$ value will be determined with the condition that the above power delivered by the source equals the dc component of the instantaneous active power demanded by the load. Therefore:

$$
K=\frac{\bar{p}_{L e}+\bar{p}_{L 0}}{u_{\alpha 1}^{2}+u_{\beta 1}^{2}}
$$

Finally, the reference source current will be given by:

$$
\left[\begin{array}{c}
i_{S 0_{\text {ref }}} \\
i_{S \alpha_{\text {ref }}} \\
i_{S \beta_{\text {ref }}}
\end{array}\right]=K\left[\begin{array}{c}
0 \\
u_{\alpha 1} \\
u_{\beta 1}
\end{array}\right]=\frac{\bar{p}_{L e}+\bar{p}_{L 0}}{u_{\alpha 1}^{2}+u_{\beta 1}^{2}}\left[\begin{array}{c}
0 \\
u_{\alpha 1} \\
u_{\beta 1}
\end{array}\right]
$$

\begin{tabular}{|c|c|c|c|c|c|}
\hline$p-q$ strategy & $\begin{array}{l}i_{S 0_{\text {ref }}} \\
i_{S \alpha_{\text {ref }}} \\
i_{S \beta_{r e f}}\end{array}$ & $=\frac{\bar{p}_{L}+\bar{p}_{L 0}}{u_{\alpha}^{2}+u_{\beta}^{2}}$ & $\left.\begin{array}{c}0 \\
u_{\alpha} \\
u_{\beta}\end{array}\right]$ & & \\
\hline $\begin{array}{c}i_{d}-i_{q} \\
\text { strategy }\end{array}$ & $\begin{array}{l}i_{S 0_{\text {ref }}} \\
i_{S \alpha_{\text {ref }}} \\
i_{S \beta_{\text {ref }}}\end{array}$ & $=\frac{\bar{p}_{L e}}{\left(\sqrt{u_{\alpha}^{2}+u}\right.}$ & 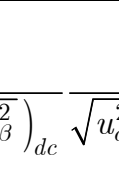 & $\frac{1}{2+u_{\beta}^{2}}$ & {$\left[\begin{array}{c}0 \\
u_{\alpha} \\
u_{\beta}\end{array}\right.$} \\
\hline $\begin{array}{l}U P F \\
\text { strategy }\end{array}$ & $\begin{array}{l}i_{S 0_{\text {ref }}} \\
i_{S \alpha_{\text {ref }}} \\
i_{S \beta_{\text {ref }}}\end{array}$ & $=\frac{\bar{p}_{L e}+}{\left(u_{0}^{2}+u_{\alpha}^{2}\right.}$ & $\frac{\bar{p}_{L 0}}{\left.+u_{\beta}^{2}\right)_{d c}}$ & $\begin{array}{l}u_{0} \\
u_{\alpha} \\
u_{\beta}\end{array}$ & \\
\hline $\begin{array}{l}P H C \\
\text { strategy }\end{array}$ & $\begin{array}{l}i_{S 0_{\text {ref }}} \\
i_{S \alpha_{\text {ref }}} \\
i_{S \beta_{r e f}}\end{array}$ & $=\frac{\bar{p}_{L e}+\bar{p}_{L 0}}{u_{\alpha 1}^{2}+u_{\beta 1}^{2}}$ & {$\left[\begin{array}{c}0 \\
u_{\alpha 1} \\
u_{\beta 1}\end{array}\right.$} & & \\
\hline
\end{tabular}

\section{Comparative evaluation}

Table I summarizes the expressions for determining the reference source current in the four compensation strategies considered.

TABLA I. - Expressions for determining the reference source current. 
For comparative evaluation, various simulation results are obtained under both ideal and distorted mains voltage and under different load current conditions. In all the cases, the phase angle between the fundamental components of source voltage and load current is $30^{\circ}$ inductive.

Following figures are based on normalized quantities. For balanced cases the phase $a$ magnitudes will be shown, for unbalanced cases all three phases magnitudes will be shown. For all cases, the information is organized in this manner:

(a) Source voltage and load current.

(b) Frequency spectrum of source voltage and load current.

(c) Reference compensator current: UPF (blue), $p-q$ (green), $i_{d}-i_{q}$ (red), PHC (cyan).

(d) Reference source current with the same colors assignation as in (c).

(e) Frequency spectrum of $i_{\text {Sref }}$ for $U P F$ strategy.

(f) Frequency spectrum of $i_{\text {Sref }}$ for $p-q$ strategy.

(g) Frequency spectrum of $i_{\text {Sref }}$ for $d-q$ strategy.

(h) Frequency spectrum of $i_{\text {Sref }}$ for PHC strategy.

(i) Load powers: $p_{e}$ (blue), $q$ (green), $p_{0}$ (red).

(j) Source powers for UPF: $p_{e}$ (blue), $q$ (green), $p_{0}$ (red).

(k) Source powers for $p-q$ : $p_{e}$ (blue), $q$ (green), $p_{0}$ (red).

(l) Source powers for $d-q$ : $p_{e}$ (blue), $q$ (green), $p_{0}$ (red).

(m) Source powers for PHC: $p_{e}$ (blue), $q$ (green), $p_{0}$ (red).

Case A. Ideal mains voltage. Balanced and distorted ( $5^{\text {th }}$ and $7^{\text {th }}$ harmonic) load current.
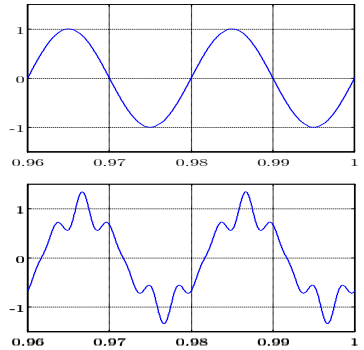

(a)

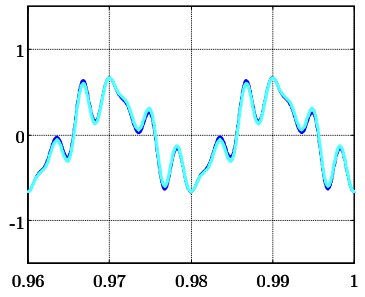

(c)

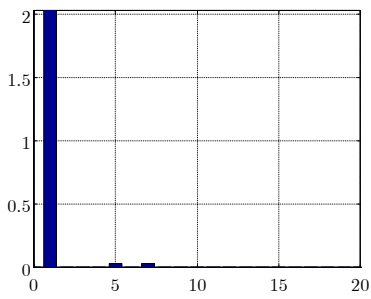

(e)
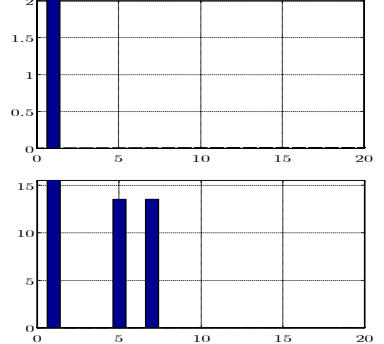

(b)

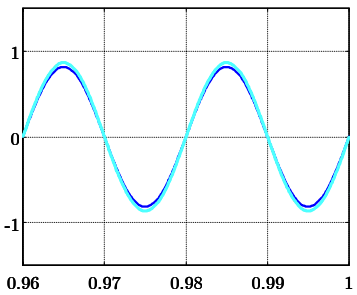

(d)

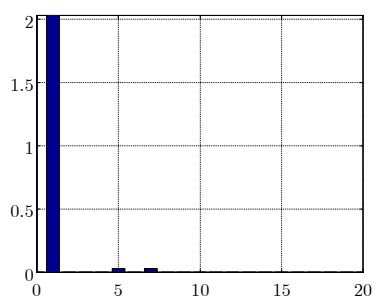

(f)

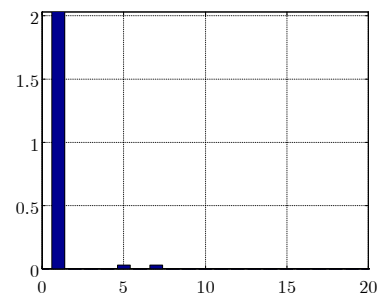

(g)

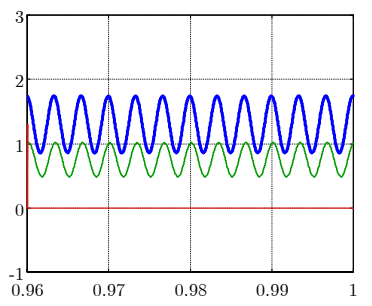

(i)

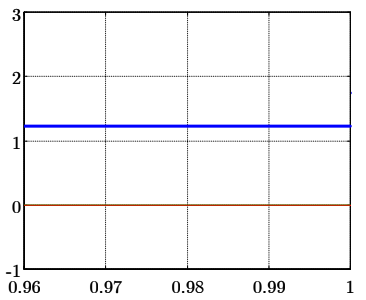

(j)

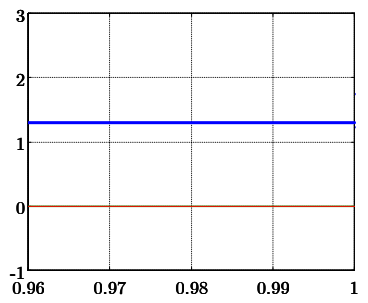

(1)

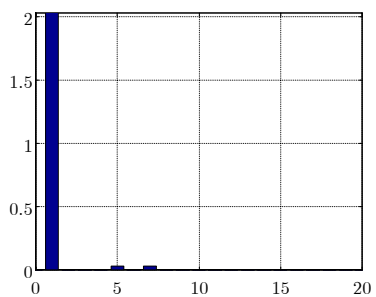

(h)

$$
\begin{aligned}
& \bar{p}_{L e}=\bar{p}_{L e 1}=1,299 \\
& \bar{q}_{L}=\bar{q}_{L 1}=0,750 \\
& p_{L 0}=0
\end{aligned}
$$

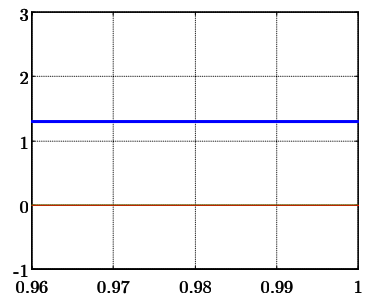

(k)

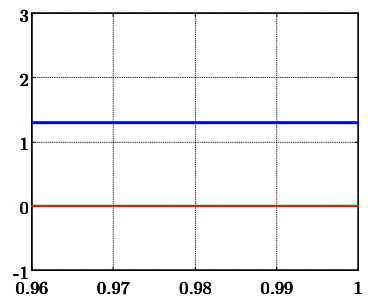

(m)

Fig. 2. Simulation results for case A.

Simulation results for case A are shown in Figure 2 and Table II. It is observed that both source voltages and current are sinusoidals, and are in phase, hence, reactive power and harmonics are fully compensated. The source supplies only the constant power demanded by the load..

TABLE II: Summary of values from simulation results for case $A$.

\begin{tabular}{|l|l|l|l|l|l|}
\hline & $i_{L}$ & $i_{S} U P F$ & $i_{S} p-q$ & $i_{S} d-q$ & $i_{S} P H C$ \\
\hline$T H D$ & $24,46 \%$ & $0,036 \%$ & $0,041 \%$ & $0,041 \%$ & $0,044 \%$ \\
\hline$I_{I}(\mathrm{~A})$ & 0,707 & 0,577 & 0,612 & 0,612 & 0,612 \\
\hline$I(\mathrm{~A})$ & 0,728 & 0,577 & 0,612 & 0,612 & 0,612 \\
\hline $\cos \phi_{I}$ & 0,866 & 1 & 1 & 1 & 1 \\
\hline$p f$ & 0,841 & 1 & 1 & 1 & 1 \\
\hline$S$ (VA) & 1,544 & 1,225 & 1,299 & 1,299 & 1,299 \\
\hline
\end{tabular}


Case B. Balanced and distorted ( $5^{\text {th }}$ and $7^{\text {th }}$ harmonic) source voltages. Balanced and distorted $\left(5^{\text {th }}\right.$ and $7^{\text {th }}$ harmonic) load currents.

Simulation results for case B are shown in Figure 3 and Table III. It is observed that, for UPF strategy, both source voltages and currents have similar shape, and are in phase; hence, reactive power is fully compensated and harmonic levels of the compensated (source) currents are the same as in the source voltages. On the other hand, $i_{d}$ $i_{q}$ and $P H C$ strategies reduce distortion but the reactive power is not fully compensated. With $p-q$ strategy, source currents contain harmonics at frequencies not present in load currents, but only with this strategy the source supplies the constant power demanded by the load.

TABLA III: Summary of values from simulation results for case $B$

\begin{tabular}{|l|l|l|l|l|l|}
\hline & $i_{L}$ & $i_{S} U P F$ & $i_{S} p-q$ & $i_{S} d-q$ & $i_{S} P H C$ \\
\hline$T H D$ & $24,46 \%$ & $24,29 \%$ & $25,79 \%$ & $4,232 \%$ & $0,045 \%$ \\
\hline$I_{I}(\mathrm{~A})$ & 0,707 & 0,542 & 0,611 & 0,610 & 0,575 \\
\hline$I(\mathrm{~A})$ & 0,728 & 0,559 & 0,631 & 0,611 & 0,575 \\
\hline $\cos \phi_{1}$ & 0,866 & 1 & 1 & 1 & 1 \\
\hline$p f$ & 0,768 & 1 & 0,885 & 0,972 & 0,971 \\
\hline$S(\mathrm{VA})$ & 1,590 & 1,220 & 1,379 & 1,334 & 1,257 \\
\hline
\end{tabular}
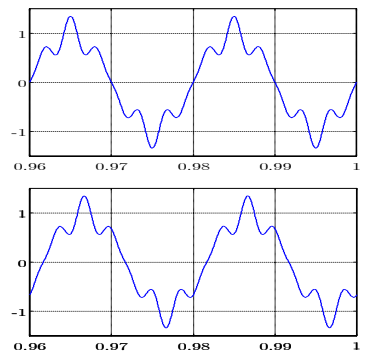

(a)

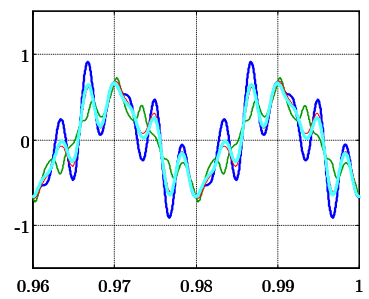

(c)

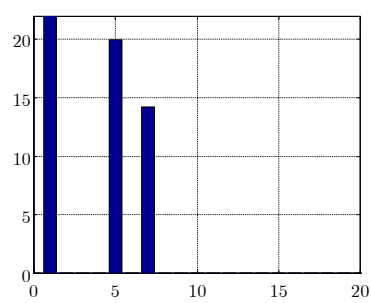

(e)
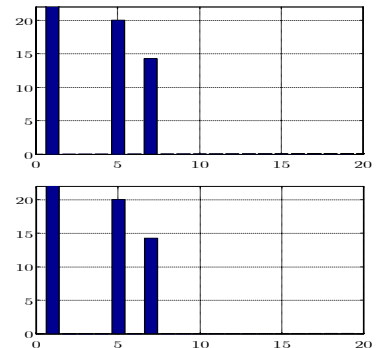

(b)

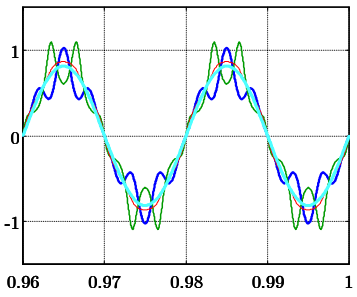

(d)

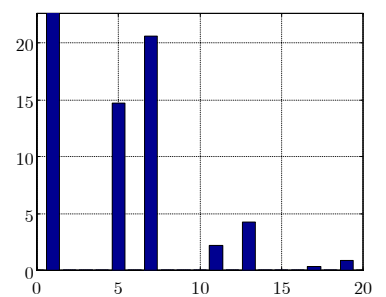

(f)

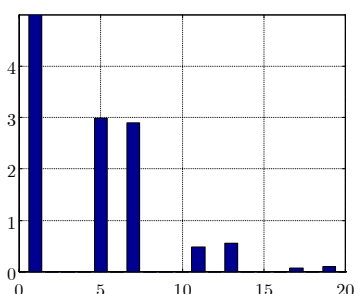

(g)

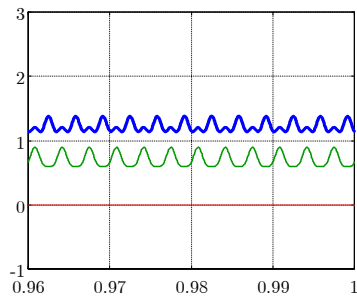

(i)

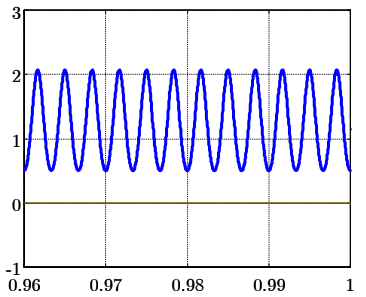

(j)

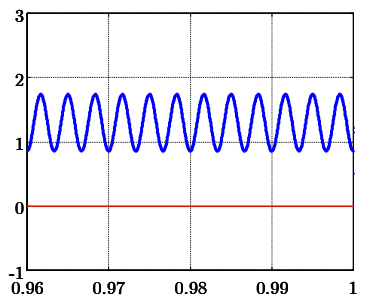

(1)

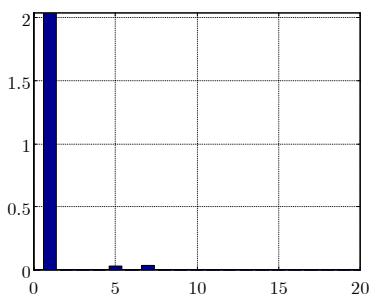

(h)

$$
\begin{aligned}
& \bar{p}_{L e}=1,221 \\
& \bar{p}_{L e 1}=1,299 \\
& \bar{q}_{L}=0,765 \\
& \bar{q}_{L 1}=0,750 \\
& p_{L 0}=0
\end{aligned}
$$

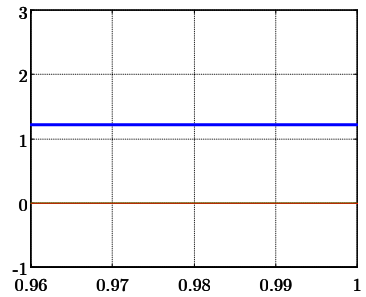

(k)

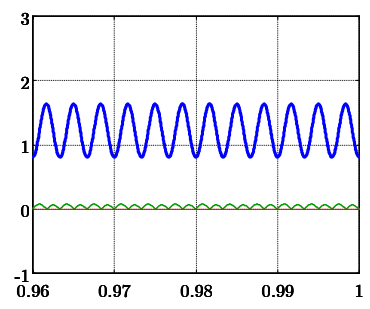

(m)

Fig. 3: Simulation results for case $B$

All the strategies correctly compensate the fundamental component reactive power. However, with $P H C$ strategy the source supplies oscillating reactive power.

Case C. Balanced and distorted ( $7^{\text {th }}$ harmonic) source voltage. Balanced and distorted ( $5^{\text {th }}$ harmonic) load current.

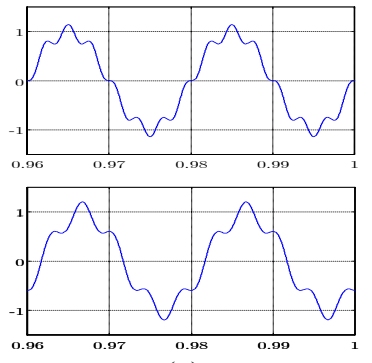

(a)
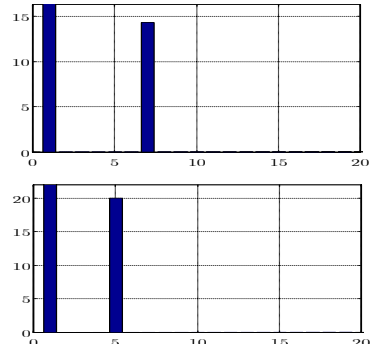

(b) 


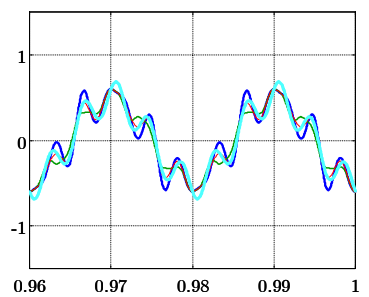

(c)

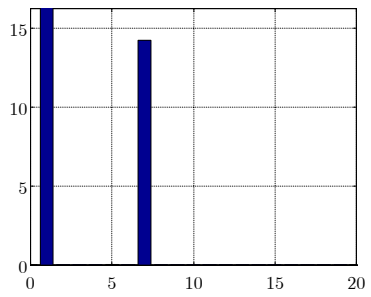

(e)

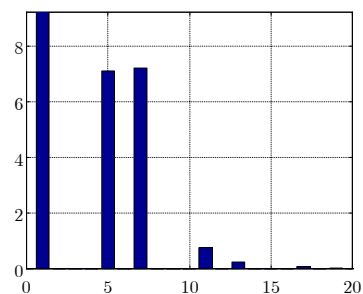

(g)

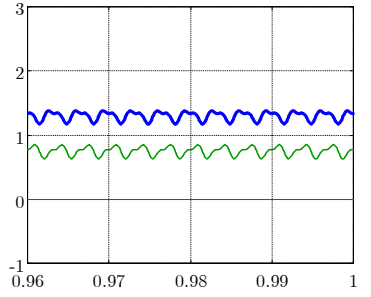

(i)

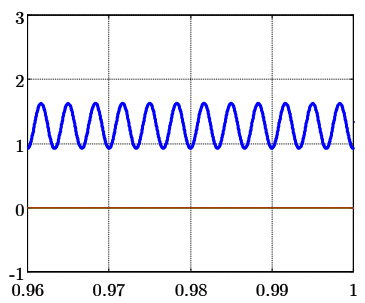

(j)

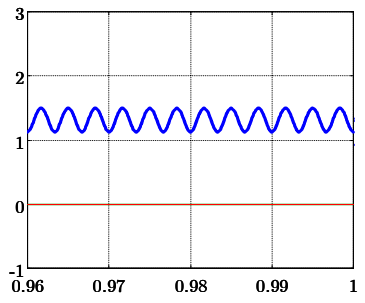

(1)

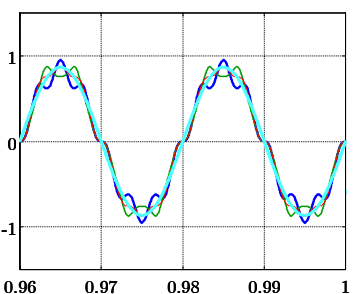

(d)

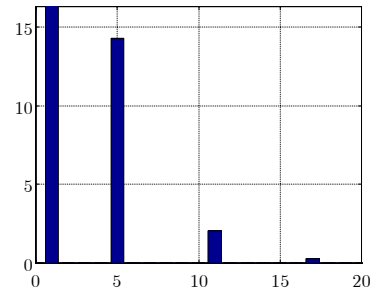

(f)

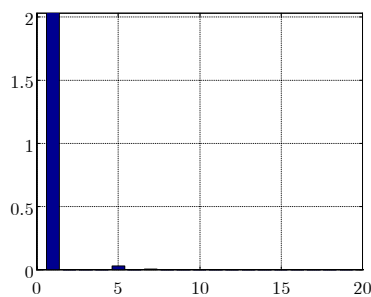

(h)

$$
\begin{aligned}
& \bar{p}_{L e}=\bar{p}_{L e 1}=1,221 \\
& \bar{q}_{L}=\bar{q}_{L 1}=0,750 \\
& p_{L 0}=0
\end{aligned}
$$

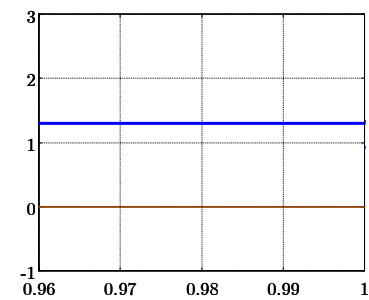

(k)

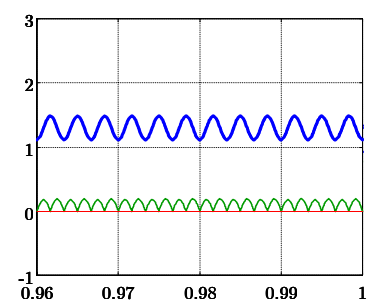

(m)

Fig. 4: Simulation results for case $C$

Simulation results for case $\mathrm{C}$ are shown in Figure 4 and Table IV. These results are similar to the case B: Note that $i_{d}-i_{q}$ strategy generates non-sinusoidal reference source currents due to the different harmonics order in source voltages and load currents.

TABLA IV: Summary of values from simulation results for case $C$

\begin{tabular}{|l|l|l|l|l|l|}
\hline & $i_{L}$ & $i_{S} U P F$ & $i_{S} p-q$ & $i_{S} d-q$ & $i_{S} P H C$ \\
\hline$T H D$ & 19,887 & 14,255 & 14,429 & 10,160 & 0,03 \\
\hline$I_{l}(\mathrm{~A})$ & 0,707 & 0,589 & 0,612 & 0,615 & 0,612 \\
\hline$I(\mathrm{~A})$ & 0,721 & 0,595 & 0,619 & 0,618 & 0,612 \\
\hline $\cos \phi_{I}$ & 0,866 & 1 & 1 & 1 & 1 \\
\hline$p f$ & 0,841 & 1 & 0,980 & 0,995 & 0,990 \\
\hline$S(\mathrm{VA})$ & 1,545 & 1,274 & 1,326 & 1,324 & 1,312 \\
\hline
\end{tabular}

Case D. Unbalanced and undistorted source voltages. Unbalanced and undistorted load currents.

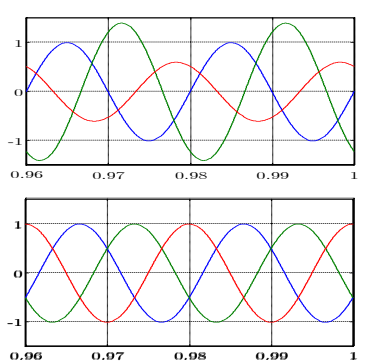

(a)

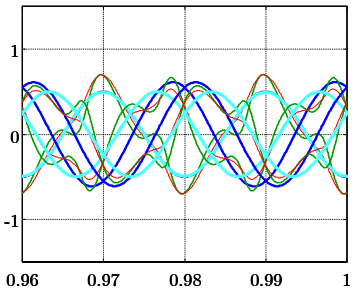

(c)

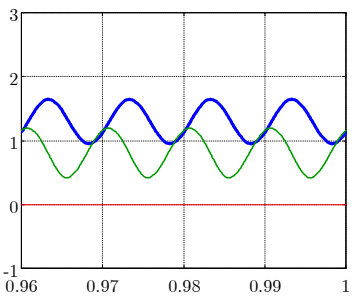

(i)

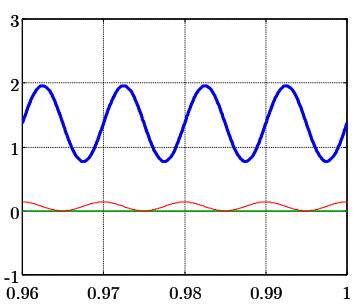

(j)

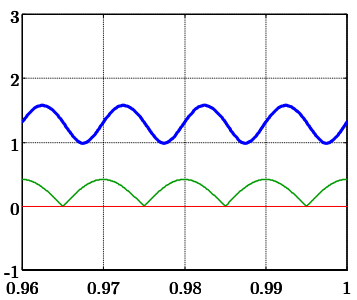

(1)
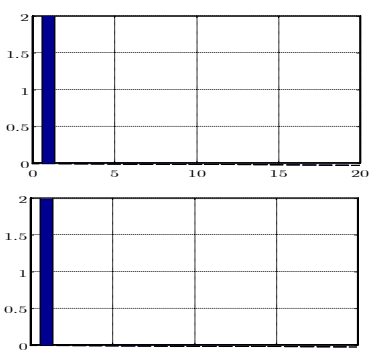

(b)

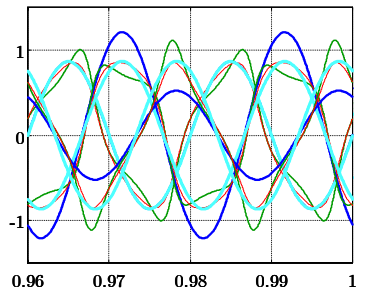

(d)

$$
\begin{aligned}
& \bar{p}_{L e}=\bar{p}_{L e 1}=1,299 \\
& \bar{q}_{L}=\bar{q}_{L 1}=0,75 \\
& p_{L 0}=0
\end{aligned}
$$

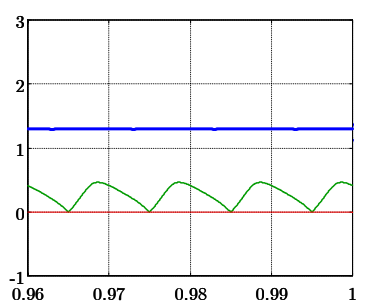

(k)

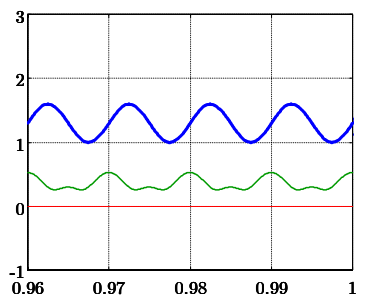

(m)

Fig. 5: Simulation results for case $D$ 
Simulation results for case D are shown in Figure 5 and Table V. It is observed that only PHC strategy is able to eliminate unbalance from the load currents. The frequency spectrums in Figure 5 do not appear because they are different for each phase, however THD values are shown in Table $\mathrm{V}$. The $p-q$ strategy obtains the worst results, instead. With $P H C$ strategy the source supplies high oscillating reactive power which is not demanded by the load.

TABLA V: Summary of values from simulation results for case $D$

\begin{tabular}{|l|l|l|l|l|l|}
\hline & $i_{L}$ & $i_{S} U P F$ & $i_{S} p-q$ & $i_{S} d-q$ & $i_{S} P H C$ \\
\hline$I_{A}(\mathrm{~A})$ & 0,707 & 0,612 & 0,630 & 0,603 & 0,612 \\
$T H D$ & $0 \%$ & $0,225 \%$ & $23,96 \%$ & $11,6 \%$ & $0,224 \%$ \\
\hline$I_{B}(\mathrm{~A})$ & 0,707 & 0,856 & 0,629 & 0,662 & 0,611 \\
$T H D$ & $0 \%$ & $0 \%$ & $23,76 \%$ & $10,67 \%$ & $0 \%$ \\
\hline$I_{C}(\mathrm{~A})$ & 0,707 & 0,368 & 0,631 & 0,541 & 0,613 \\
$T H D$ & $0 \%$ & $0 \%$ & $23,77 \%$ & $11,94 \%$ & $0 \%$ \\
\hline$p f$ & 0,866 & 1 & 0,9733 & 0,9822 & 1 \\
\hline$S(\mathrm{VA})$ & 1,5 & 1,435 & 1,335 & 1,31 & 1,297 \\
\hline
\end{tabular}

Case E. Unbalanced and undistorted source voltages. Unbalanced and undistorted load currents.
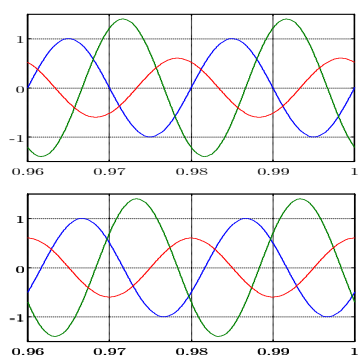

(a)

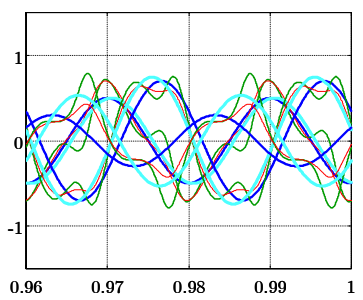

(c)

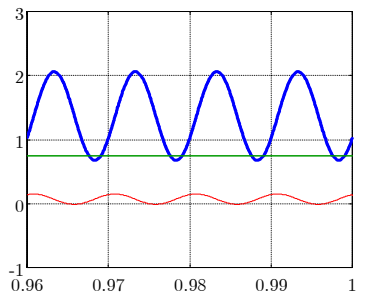

(i)

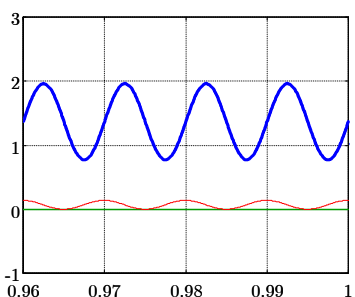

(j)

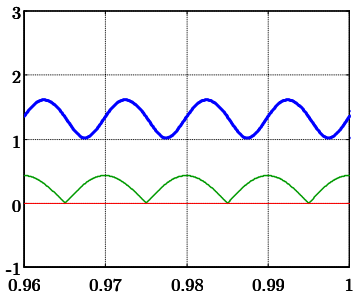

(1)

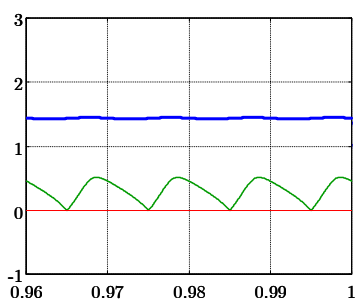

(k)

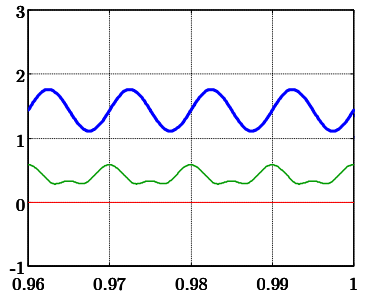

(m)
Fig. 6: Simulation results for case $E$

TABLA VI: Summary of values from simulation results for case $E$

\begin{tabular}{|l|l|l|l|l|l|}
\hline & $i_{L}$ & $i_{S} U P F$ & $i_{S} p-q$ & $i_{S} d-q$ & $i_{S} P H C$ \\
\hline$I_{A}(\mathrm{~A})$ & 0,707 & 0,613 & 0,697 & 0,619 & 0,677 \\
$T H D$ & $0 \%$ & $0,204 \%$ & $24,15 \%$ & $11,82 \%$ & $0,161 \%$ \\
\hline$I_{B}(\mathrm{~A})$ & 0,99 & 0,855 & 0,695 & 0,679 & 0,675 \\
$T H D$ & $0 \%$ & $0 \%$ & $24 \%$ & $10,9 \%$ & $0 \%$ \\
\hline$I_{C}(\mathrm{~A})$ & 0,424 & 0,367 & 0,7 & 0,557 & 0,68 \\
$T H D$ & $0 \%$ & $0 \%$ & $23,92 \%$ & $12,14 \%$ & $0 \%$ \\
\hline$p f$ & 0,866 & 1 & 0,973 & 0,99 & 1 \\
\hline$S(\mathrm{VA})$ & 1,659 & 1,436 & 1,478 & 1,346 & 1,435 \\
\hline
\end{tabular}

Simulation results for case E are shown in Figure 6 and Table VI. Here, in contrast to case D, there is zerosequence instantaneous power. In all strategies the constant power component is supplied by the source $\left(\bar{p}_{S e}=\bar{p}_{L e}+\bar{p}_{L 0}\right)$, except in $i_{d}-i_{q}$ strategy in which the mentioned power is supplied by the compensator, as can be seen in equation (13).

\section{Conclusions}

The most appropriate strategy depends on the correction objective. If the compliance of harmonic standards and reactive power compensation are looked for, the $P H C$ is the most adequate strategy, because it acts correctly under any utility conditions. If minimizing the source currents RMS values is desired, the best strategy is $U P F$, even more in the presence of harmonic voltages at the PCC not caused by the nonlinear load. If constant active power from the source is desired, the generalized $p-q$ theory will be selected, although it maintains or increase the source current harmonic distortion. The $i_{d}-i_{q}$ theory could be considered an intermediate solution among all strategies because it maintains all the ratios under certain limits.

It has been proved that $p-q$ strategy (maybe the most widely used) is the most sensitive to distortion and imbalance in the voltages at the PCC. 


\section{References}

[1] Akagi, H.; Kanazawa, Y.; Nabae, A. "Instantaneous Reactive Power Compensators Comprising Switching Devices without Energy Storage Components", IEEE Transactions on Industry Applications, Vol. 20, No 3, pp. 625 - 630. MayJune 1984.

[2] Peng, F.-Z.; Ott, G. W.; Adams, D. J. "Harmonic and Reactive Power Compensation Based on the Generalized Instantaneous Reactive Power Theory for Three-Phase Four-Wire Systems", IEEE Transactions on Power Electronics, Vol. 13, No 6, pp. 1174-1181. November 1998.

[3] Akagi, H.; Ogasawara, S.; Kim, H. "The Theory of Instantaneous Power in Three-Phase Four-wire systems: A comprehensive approach", Conf. Rec. IEEE-IAS Annual Meeting, pp. 431 - 439, 1999.

[4] Afonso, J.; Couto, C.; Martins, J. "Active Filters with Control Based on the p-q Theory", IEEE Industrial Electronics Society Newsletter, pp. 5 11. September 2000.

[5] Aredes, M.; Watanabe, E.H. "New Control Algorithms for Series and Shunt Three-phase Fourwire Active Power Filters", IEEE Transactions on Power Delivery, Vol. 11, No 3, pp. 1649 - 1656. July 1995.
[6] Nabae, A; Tanaka, T. "A New Definition of Instantaneous Active-Reactive Current anda Power Based on Instantaneous Space Vectors on Polar Coordinates in Three Phase Circuits", IEEE Transactions on Power Delivery, Vol. 11, No 3, pp. 1238 - 1243. July 1996.

[7] Soares, V.; Verdelho, P.; Marques, G. D. "An Instantaneous Active and Reactive Current Component Method for Active Filters", IEEE Transactions on Power Electronics, Vol. 15, $\mathrm{N}^{\circ} 4$, pp. 660-669. July 2000.

[8] Rafiei, M.-R.; Toliyat, H. A.; Ghazi, R.; Gopalarathanam, T. "An Optimal and Flexible Control Strategy for Active Filtering and Power Factor Correction Under Non-Sinusoidal Line Voltages", IEEE Transactions on Power Delivery, Vol. 16, No. 2, pp 297-305, April 2001.

[9] Cavallani, A.; Montarani, G.C. "Compensation Strategies for Shunt Active-filter Control", IEEE Transactions on Power Electronics, Vol. 9, No 6, November 1984

[10] Depenbrock, M.; Staudt, V.; Wrede, H. "A Theoretical Investigation of Original and Modified Instantaneous Power Theory Applied to Four-Wire Systems", IEEE Transactions on Industry Applications, Vol. 39, No 4, pp. 1160-1168. JulyAugust 2003. 